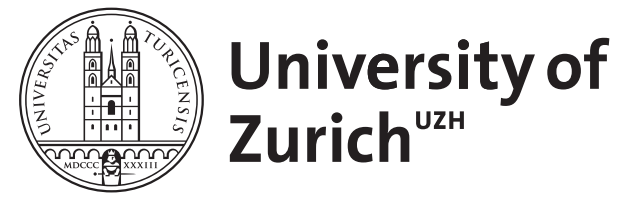

Zurich Open Repository and Archive

University of Zurich

University Library

Strickhofstrasse 39

CH-8057 Zurich

www.zora.uzh.ch

Year: 2011

\title{
Metallothioneins: chemical and biological challenges
}

Vašák, M

DOI: https://doi.org/10.1007/s00775-011-0832-5

Posted at the Zurich Open Repository and Archive, University of Zurich

ZORA URL: https://doi.org/10.5167/uzh-49996

Journal Article

Published Version

Originally published at:

Vašák, M (2011). Metallothioneins: chemical and biological challenges. Journal of Biological Inorganic Chemistry, 16(7):975-976.

DOI: https://doi.org/10.1007/s00775-011-0832-5 


\title{
Metallothioneins: chemical and biological challenges
}

\author{
M. Vašák
}

Received: 26 July 2011/Accepted: 8 August 2011/Published online: 9 September 2011

(C) SBIC 2011

Metallothioneins (MTs) belong to a superfamily of intriguing low-molecular mass cysteine- and metal-rich proteins, present in all living organisms. The first MT was discovered by the late Bert L. Vallee in 1957 [1]. His work and its impact on life sciences has been discussed by Williams [2] in the In Memoriam published in this journal last year. This Special Issue is dedicated to him in appreciation of his outstanding contributions not only to the field of zinc biochemistry but also to the MT field.

Metallothioneins, in addition to carbonic anhydrase in diatoms, are the only biological compounds in which cadmium accumulates naturally, the other metallic components usually being copper and zinc. In fact, zinc and/or copper are the principal metal constituents of MTs under normal physiological conditions. The binding of these metal ions is achieved through the formation of sulfurbased metal-thiolate clusters. Metallothioneins are intracellular proteins, but in higher organisms they can also occur in the extracellular space, suggesting that they may play different biological roles depending on their localization. The majority of the MT literature has focused on

This article is part of a JBIC special issue on metallothioneins.

\section{Vašák}

Department of Biochemistry,

University of Zürich,

Winterthurerstrasse 190,

8057 Zurich, Switzerland

Present Address:

M. Vašák $(\bowtie)$

Department of Inorganic Chemistry,

University of Zürich,

Winterthurerstrasse 190,

8057 Zurich, Switzerland

e-mail: mvasak@bioc.uzh.ch vertebrate MTs in terms of their structure, function and gene regulation. Several biological roles have been ascribed to these MTs, including their involvement in zinc and copper homeostasis, the protection against environmental heavy metals and oxidative stress, the control of redox status of the cell, the antiapoptotic role, and recently in the protection and regeneration of the mammalian brain following neurological injury and disease. Thus, it is increasingly clear that MTs can have multiple biological functions. The studies of vertebrate MTs led to the notion that the knowledge obtained is transferable to MTs from other phyla. However, in recent years, the characterization of bacterial and plant MTs led to unforeseen molecular properties including the participation of both cysteine and histidine in metal coordination.

This Special Issue of the Journal of Biological Inorganic Chemistry compiles a set of reviews and research articles that reflect the current knowledge regarding the chemistry and biology of MTs from various organisms, their evolutionary biology and their role in disease. Many of the foremost scientists in this field have contributed excellent overview articles. The first contribution by Capdevila and Atrian [3] discusses the unclear points of MT evolution, leading to the present problems in interpreting MT diversity and heterogeneity in terms of its molecular evolution along with new evolutionary aspects. In the overview by Palacios et al. [4], the same team proposes a new classification of the MT systems in which the metal binding preference of recombinant MTs from diverse organisms toward the physiological relevant zinc and copper ions is considered. Five contributions focus on MTs from lower organisms, namely plants, Drosophila and invertebrates. Blindauer [5], in her review, discusses the past and current views and challenges of studying the diverse family of bacterial MTs. This review also provides 
new insights into why some bacteria might have evolved to sequester surplus metals in these proteins while others export the excess across the plasma-membrane. Gutiérrez et al. [6] give an overview on ciliate MTs (Tetrahymena species), including a description of the peculiarities of their primary sequences, functional insights and their applications as biosensors in environmental toxicology. Freisinger [7] reviews the structural features of plant MTs derived from their sequences and biophysical data, with special emphasis given to the structural and functional aspects of linker sequences typical for these MTs. Drosophila melanogaster represents the well-known model organism in molecular genetics. In an original research article by Atanesyan et al. [8], a new fifth member of the Drosophila MT gene family $(M t n E)$ was identified and its transcriptional regulation studied. The molecular and cellular mechanisms of the multifunctional MTs from two distinct invertebrates, nematodes and snails, are compared in the review by Höckner et al. [9]. Another group of contributions focuses on the chemistry and biology of vertebrate MTs and their role in disease. Vašák and Meloni [10], in their review, after a brief summary of the historical milestones of the mammalian MT-1/MT-2 research, discuss the advances in the structure, chemistry and biological functions of the more recently discovered mammalian MT-3 and MT-4 isoforms. The review by Maret [11] summarizes important aspects of redox biochemistry of mammalian MTs in relation to their function in redox-dependent zinc metabolism. Namdarghanbari et al. [12] provide a comprehensive review of the role of mammalian MT-1/MT-2 in toxicology, cancer and chemotherapy. A paper by Manso et al. [13] first provides an overview of the general aspects of the inflammatory responses along with the function of MTs in neuroinflammation of the central nervous system. This is followed by the first data obtained on an Alzheimer disease mouse model treated with human MT-2A. West et al. [14] provide a comprehensive review of the extracellular roles of MTs in the brain and their interactions with the lipoprotein receptor-related proteins. Mammalian MTs represent the major Zn-binding proteins in the cell. Zinc has emerged not only as a major regulator of neuronal physiology but also as an important intracellular signaling agent similar to calcium. The review by Fukada et al. [15] describes the role of abnormal zinc homeostasis in multiple diseases and the role of this ion in cellular signaling.

Overall, despite an extensive literature following the discovery of MTs more than 50 years ago, this class of proteins is still attracting considerable interest of researchers from many fields. I hope that the review articles presented in this Special Issue will help stimulate further study into the biological functions and bioinorganic chemistry of MTs and possibly uncover unexpected features of these important proteins. I wish to thank the members of the JBIC editorial board for making this Special Issue possible and Deborah Schoenholz for her help in organizing this issue.

\section{References}

1. Margoshes M, Vallee BL (1957) J Am Chem Soc 79:4813-4814

2. Williams RJP (2010) J Biol Inorg Chem 15:1175-1176

3. Capdevila M, Atrian S (2011) J Biol Inorg Chem. doi: 10.1007/s00775-011-0798-3

4. Palacios O, Atrian S, Capdevila M (2011) J Biol Inorg Chem. doi: 10.1007/s00775-011-0827-2

5. Blindauer C (2011) J Biol Inorg Chem. doi:10.1007/s00775-0110790-y

6. Gutiérrez JC, Amaro F, Diaz S, de Francisco P, Cubas L, MartinGonzalez A (2011) J Biol Inorg Chem. doi:10.1007/s00775-0110820-9

7. Freisinger E (2011) J Biol Inorg Chem. doi:10.1007/s00775011-0801-z

8. Atanesyan L, Günther V, Georgiev O, Celniker SE, Schaffner W (2011) J Biol Inorg Chem. doi:10.1007/s00775-011-0825-4

9. Höckner M, Dallinger R, Stürzenbaum SR (2011) J Biol Inorg Chem. doi:10.1007/s00775-011-0826-3

10. Vašák M, Meloni G (2011) J Biol Inorg Chem. doi:10.1007/ s00775-011-0799-2

11. Maret W (2011) J Biol Inorg Chem. doi:10.1007/s00775-0110800-0

12. Namdarghanbari M, Wobig W, Krezoski S, Tabatabai N, Petering DH (2011) J Biol Inorg Chem. doi:10.1007/s00775-011-0823-6

13. Manso Y, Adlard PA, Carrasco J, Vašák M, Hidalgo J (2011) J Biol Inorg Chem. doi:10.1007/s00775-011-0802-y

14. West AK, Leung J, Chung R (2011) J Biol Inorg Chem. doi: 10.1007/s00775-011-0817-4

15. Fukada T, Yamasaki S, Keigo N, Murakami M, Hirano T (2011) J Biol Inorg Chem. doi:10.1007/s00775-011-0797-4 